\title{
An economic examination of private insurance claims among adolescents and young adults who were enrolled in hospice during the last year of life
}

This article was published in the following Dove Press journal: Adolescent Health, Medicine and Therapeutics

\author{
Jessica Keim-Malpass ${ }^{1,2}$ \\ Austin C Cohrs ${ }^{3}$ \\ Lisa C Lindley ${ }^{4}$ \\ Douglas L Leslie ${ }^{3}$ \\ 'Department of Acute and Specialty \\ Care, School of Nursing, University \\ of Virginia, Charlottesville, VA, USA; \\ ${ }^{2}$ Department of Pediatrics, School \\ of Medicine, University of Virginia, \\ Charlottesville, VA, USA; ${ }^{3}$ Department \\ of Public Health Sciences, Penn State \\ College of Medicine, Hershey, PA, \\ USA; ${ }^{4}$ College of Nursing, University \\ of Tennessee-Knoxville, Knoxville, TN, \\ USA
}

Purpose: The purpose of this study was to generate baseline data on the health characteristics, health care utilization, and health care spending among privately insured adolescents and young adults (AYA), who were enrolled in hospice care during their last year of life.

Methods: A retrospective, nonexperimental design was used to collect and analyze longitudinal claims data from the Truven Health MarketScan ${ }^{\mathrm{TM}}$ database. The sample included AYA (aged 15-24 years) who utilized hospice during their last year of life.

Results: Totally, 17,408 AYA were included in this analysis. Mean hospice length of stay (LOS) was low overall, but there was a statistically significant difference in hospice LOS in ages 15-19 years (mean 3.56, SD 15.17 days) compared with those aged 20-24 years (mean 2.26, SD 8.24; $P<0.001$ days). More than a third (37\%) of the AYAs used the emergency department during the last year of life and $83 \%$ sought care from a primary care visit. However, only $6 \%$ of the sample who were hospice enrollees used frequent inpatient hospital services.

Conclusions: This study provides preliminary data for private insurance expenditures and clinical utilization for AYA who were enrolled in hospice. This analysis also provides initial evidence to suggest extremely short hospice LOS for AYAs prior to the end of life and represents an area of future research need.

Keywords: adolescent, young adult, hospice, economic, private health insurance, end of life

\section{Introduction}

Relatively little is known about the end of life (EOL) trajectories of adolescents and young adults (AYA; aged 15-24 years) with life-limiting illnesses. In this context, EOL trajectories represent utilization patterns prior to the EOL in regards to costs, provider visits, hospitalizations, interventions, and general access to the health care system. ${ }^{1}$ Of the reports that exist, most focus on AYA with cancer. ${ }^{1-5}$ Roughly three-fourths of young people who die do so in an intensive care setting with numerous burdensome symptoms and distress at the EOL. ${ }^{6}$ There is a dearth of information on the influence of hospice care on AYA's EOL quality care outcomes. What is known suggests that hospice care allows for a comprehensive and family-centered approach at the EOL that incorporates symptom management, psychosocial and spiritual support, life review, and goal setting for those with a life expectancy of $\leq 6$ months. ${ }^{6-8}$ Hospice care is reimbursed by both Medicare and Medicaid, and individuals who are not covered by either of these entities must acquire private insurance to receive hospice care benefits. ${ }^{9}$
Correspondence: Jessica Keim-Malpass School of Nursing, University of Virginia, P.O. Box 800782, Charlottesville, VA 22908-0782, USA

$\mathrm{Tel}+\mid 434243396$ I

Email Jlk2t@virginia.edu 
AYAs with life-limiting illness are at risk of receiving fragmented care due to having both pediatric and adult health care providers, along with multiple transitions between environments of care. Even within the adolescent and young adult age group, preliminary evidence suggests that young adults (aged 20-24 years) are at great risk due to care transitions both in providers and insurance coverage, but most of this literature has been limited to those with cancer diagnoses. ${ }^{5,10,11}$ To our knowledge, examination of hospice care use has not yet been explored for young people who are covered through private insurance. Thus, the purpose of this study was to generate baseline data on the health characteristics, health care utilization, and health care spending among privately insured AYA, who enrolled in hospice care during their last year of life. A secondary purpose of this study was to explore differences in hospice length of stay (LOS) between adolescents (aged 15-19 years) and young adults (aged 20-24 years).

\section{Methods}

\section{Data source}

We analyzed de-identified claims data contained within the Truven Health Marketscan ${ }^{\mathrm{TM}}$ Commercial Claims and Encounters database. ${ }^{12}$ This national database provides individual-level data from active employees, early retirees, Consolidated Omnibus Budget Reconciliation Act continues, and dependents, who are insured from employer-sponsored plans. ${ }^{12}$ These data link paid claims and encounter data to detailed patient information across sites and types of providers and over time. Quality standards for the MarketScan Research Databases are maintained by Truven. ${ }^{8}$ The study was approved by the Penn State College of Medicine Institutional Review Board prior to study start.

\section{Cohort selection}

\section{Variables of interest}

Variables used in this analysis included 1) demographic characteristics (year enrolled, age, sex, region, and metropolitan [rural vs urban] assessment); 2) health characteristics of AYA (assessment of complex chronic conditions [CCCs] based on ICD-9 codes developed by Feudtner et $\mathrm{al}^{13}$ ); 3) health insurance plan characteristics (plan type and relation to employee); 4) utilization (hospice LOS, primary care use, hospital use [three or more hospital admissions], emergency department use, procedure use); and 5) spending (monthly net insurance payment, monthly total payment, monthly copayment, monthly deductible, monthly coinsurance, monthly coordination of benefits) adjusted to 2014 dollars. Monthly net insurance pay- ment is calculated by total payment minus deductible minus copayment minus coinsurance minus coordination of benefits.

\section{Analysis}

Descriptive statistics including frequencies, mean, standard deviations, and ranges were calculated on all variables in the sample. Analysis of variance was used to compare mean hospice LOS (15-19 vs 20-24 years). Values for spending variables were winsorized at the 1st and 99th percentiles to minimize the influence of outliers.

\section{Results}

Our sample comprised 17,408 AYA who used hospice care services during the last year of life. Demographic characteristics of the sample can be found in Table 1. The majority of the sample was derived from years 2010-2014, aged 20-24, female, and resided in urban settings in the South. Approximately $20 \%$ of the sample had a CCC documented within the year prior to death, of which malignancy was the most common $(n=1,708)$. Additionally, the majority of the sample had a preferred provider organization for plan type (63.2\%) followed by a point of service (POS) plan (26.9\%). In terms of the relation to the employee with the private insurance, $59.2 \%$ of the AYA in this sample were listed as "child", $35.8 \%$ were themselves the employee, and $4.7 \%$ were classified as "spouse".

Spending and utilization data are displayed in Table 2. More than a third (37\%) of the AYAs used the emergency department during the last year of life and $83 \%$ sought care from a primary care visit. However, only $6 \%$ of the sample used frequent inpatient hospital services (more than three times) during this EOL trajectory. There was a statistically significant difference in hospice LOS among those aged 15-19 years (mean 3.56, SD 15.17 days) compared with those aged 20-24 years (mean 2.26, SD 8.24 days; $P<0.001$ ). The AYA in this sample had average net insurance payments that exceeded $\$ 2,000$ per month.

\section{Discussion}

This study provides preliminary data on health care utilization and spending for AYA who were enrolled in hospice. AYA in this sample had relatively high primary care utilization and very few had recurrent hospitalizations. The average hospice LOS was low, with adolescents having longer LOS in hospice than young adults. This finding was consistent with other reports of children and adolescents. ${ }^{2,14}$ From a developmental perspective, AYAs at the EOL are at particular 
Table I Patient demographics and health characteristics $(\mathrm{n}=17,408)$

\begin{tabular}{|c|c|c|}
\hline Variable & Frequency & Percent \\
\hline \multicolumn{3}{|l|}{ Years enrolled } \\
\hline 2005-2009 & 3,380 & 19.4 \\
\hline $2010-2014$ & 14,028 & 80.6 \\
\hline \multicolumn{3}{|l|}{ Age (years) } \\
\hline $15-19$ & 5,761 & 33.1 \\
\hline $20-24$ & 11,647 & 66.9 \\
\hline \multicolumn{3}{|l|}{ Sex } \\
\hline Male & 5,323 & 30.6 \\
\hline Female & 12,085 & 69.4 \\
\hline \multicolumn{3}{|l|}{ Region } \\
\hline Northeast & 3,117 & 17.9 \\
\hline North central & 2,635 & I5.I \\
\hline South & 8,984 & 51.6 \\
\hline West & 2,672 & 15.4 \\
\hline \multicolumn{3}{|l|}{ Relation to insurance enrollee } \\
\hline Self & 6,226 & 35.8 \\
\hline Spouse & 821 & 4.7 \\
\hline Child & $10,36 \mid$ & 59.2 \\
\hline \multicolumn{3}{|l|}{ Insurance plan type } \\
\hline Preferred provider organization & 10,573 & 63.2 \\
\hline Point of service & 4,508 & 26.9 \\
\hline Other & 2,327 & 9.9 \\
\hline \multicolumn{3}{|l|}{ Metropolitan } \\
\hline Rural & $\mathrm{I}, 473$ & 8.5 \\
\hline Urban & 15,935 & 91.5 \\
\hline \multicolumn{3}{|l|}{ CCC category } \\
\hline Neuromuscular & 757 & $|5.6|$ \\
\hline Cardiovascular & 687 & 14.17 \\
\hline Respiratory & 65 & 1.34 \\
\hline Renal & 105 & 2.17 \\
\hline Gastrointestinal & 290 & 5.98 \\
\hline Hematology/lmmunodeficiency & 182 & 3.75 \\
\hline Metabolic & 678 & 13.99 \\
\hline Congenital(other) & 376 & 7.76 \\
\hline Malignancy & ।,708 & 35.23 \\
\hline Total (not mutually exclusive) & 4,848 & \\
\hline \multicolumn{3}{|l|}{ Number of CCCs } \\
\hline 0 & 13,930 & 80.02 \\
\hline I & 2,527 & 14.52 \\
\hline 2 & 651 & 3.74 \\
\hline 3 & 213 & 1.22 \\
\hline 4 & 64 & 0.37 \\
\hline 5 & 15 & 0.09 \\
\hline 6 & 7 & 0.04 \\
\hline 7 & I & 0.01 \\
\hline
\end{tabular}

Abbreviation: CCCs, complex chronic conditions.

risk of anticipatory grief and unmet psychosocial needs, ${ }^{15,16}$ and hospice represents a model of comprehensive care that allows for both psychological care and enhanced symptom management. ${ }^{17}$ While AYA have been a recognized population at risk of health disparities in cancer, ${ }^{18-20}$ there is a need to explore the disparities in health care among this age group beyond just those with cancer. ${ }^{10,11,21}$
Table 2 Spending and utilization of hospice enrollees

\begin{tabular}{|c|c|c|}
\hline Utilization & Frequency/Mean & Percent/SD \\
\hline \multicolumn{3}{|l|}{ Hospice LOS (days) } \\
\hline Ages $15-19$ years & 3.56 & 15.17 \\
\hline Ages $20-24$ years & 2.26 & 8.24 \\
\hline \multicolumn{3}{|l|}{ Emergency department use } \\
\hline No & 11,000 & 63.20 \\
\hline Yes & 6,408 & 36.80 \\
\hline \multicolumn{3}{|l|}{ Primary care use } \\
\hline No & 2,958 & 16.99 \\
\hline Yes & 14,450 & 83.01 \\
\hline \multicolumn{3}{|c|}{ Hospital use (more than three admissions past year) } \\
\hline No & 16,370 & 94.04 \\
\hline Yes & 1,038 & 5.96 \\
\hline \multicolumn{3}{|l|}{ Procedure classifications } \\
\hline Office visit, established & 12,104 & 6.82 \\
\hline Office visit, new & 8,475 & 4.77 \\
\hline Microbiology tests & 7,962 & 4.48 \\
\hline Lab tests & 7,482 & 4.21 \\
\hline Preventive care & 7,459 & 4.2 \\
\hline Venipuncture & 7,310 & 4.12 \\
\hline Other chemistry tests & 6,745 & 3.8 \\
\hline Routine urinalysis & 5,965 & 3.36 \\
\hline Pap smear & 5,862 & 3.3 \\
\hline Blood count & 5,285 & 2.98 \\
\hline Spending & Mean & SD \\
\hline Monthly total payment (USD) & $2,269.5 \mathrm{I}$ & $7,956.21$ \\
\hline Monthly net insurance payment & $2,113.48$ & $7,786.51$ \\
\hline Monthly copay & 14.83 & 27.76 \\
\hline Monthly deductible & 46.95 & 79.08 \\
\hline Monthly coinsurance & 54.52 & 130.83 \\
\hline Monthly coordination of benefits & 4.64 & 33.11 \\
\hline
\end{tabular}

Abbreviation: LOS, length of stay.

The majority of AYA in our study did not have a CCC documented in the year prior to their death, which suggests that their health problems might be traumatic/acute in nature. This finding could also represent a lack of ongoing International Classification of Disease (ICD-9) codification of underlying chronic conditions, which represents a limitation in using private health insurance claims data for analyses at the EOL, where the presenting problems are likely more episodic and acute in nature. Given this finding, there are numerous implications for how to involve hospice care earlier in the acute illness trajectory. Additionally, there are implications for continued coverage of those with preexisting health conditions given that over a third of this sample maintained coverage for themselves because they were the primary beneficiary of the health plan. This study also highlights the implications for seriously ill youth to be able to obtain coverage on their parents' private health insurance plan up to age of 26 years per the Affordable Care Act. ${ }^{1}$

There are several limitations to note. This database did not have any death codes, so we used end of service claims 
as a proxy for death. Additionally, those who received hospice benefits through dual coverage in Medicaid would not be captured in this analysis. More longitudinal studies are needed to determine the impact of hospice on clinical outcomes among AYA.

\section{Conclusion}

Examination of hospice care use among privately insured AYAs has not yet been explored. This analysis provides baseline data on the health characteristics, health care utilization, and health care spending among privately insured AYA, who were enrolled in hospice care during their last year of life.

\section{Disclosure}

JKM was funded as a Translational Health Institute of Virginia Scholar. The authors report no other conflicts of interest in this work.

\section{References}

1. Keim-Malpass J, Erickson JM, Malpass HC. End-of-life care characteristics for young adults with cancer who die in the hospital. J Palliat Med. 2014;17(12):1-6.

2. Keim-Malpass J, Lindley LC. End-of-life transitions and hospice utilization for adolescents: does having a usual source of care matter? J Hosp Palliat Nurs. 2017;19(4):376-382.

3. Mack JW, Chen K, Boscoe FP, et al. High intensity of end-of-life care among adolescent and young adult cancer patients in the New York State Medicaid Program. Med Care. 2015;53(12):1018-1026.

4. Snaman JM, Kaye EC, Lu JJ, Sykes A, Baker JN. Palliative care involvement is associated with less intensive end-of-life care in adolescent and young adult oncology patients. J Palliat Med. 2017;20(5):509-516.

5. Rajeshuni N, Johnston EE, Saynina O, Sanders LM, Chamberlain LJ. Disparities in location of death of adolescents and young adults with cancer: a longitudinal, population study in California. Cancer. 2017;123(21):4178-4184

6. Field MJ, Behrman RE. When children die: improving palliative and end-of-life care for children and their families. JR Soc Med. 2003;96(8): 419-420.

7. Teno JM, Gozalo PL, Bynum JPW, et al. Change in end-of-life care for medicare beneficiaries. JAMA. 2013;309(5):470-477.
8. Teno JM, Plotzke M, Gozalo P, Mor V. A national study of live discharges from hospice. J Palliat Med. 2014;17(10):1121-1127.

9. Chung K, Jahng J, Petrosyan S, Kim SI, Yim V. Assessment of levels of hospice care coverage offered to commercial managed care plan members in California: implications for the California Health Insurance Exchange. Am J Hosp Palliat Care. 2015;32(4):440-447.

10. Mack JW, Chen LH, Cannavale K, Sattayapiwat O, Cooper RM, Chao CR. End-of-life care intensity among adolescent and young adult patients with cancer in Kaiser Permanente Southern California. JAMA Oncol. 2015;1(5):592-600.

11. Mack JW, Cannavale K, Sattayapiwat $\mathrm{O}$, et al. Care in the final month of life among adolescent and young adult cancer patients in Kaiser Permanente Southern California. J Palliat Med. 2016;19(11): $1136-1141$.

12. Truven Health Analytics. Putting research data into your hands with the MarketScan databases. Available from: https://truvenhealth.com/markets/life-sciences/products/data-tools/marketscan-databases. Accessed December 21, 2017.

13. Feudtner C, Feinstein JA, Zhong W, Hall M, Dai D. Pediatric complex chronic conditions classification system version 2: updated for ICD-10 and complex medical technology dependence and transplantation. $B M C$ Pediatr. 2014;14(1):199.

14. Lindley LC, Lyon ME. A profile of children with complex chronic conditions at end of life among Medicaid beneficiaries: implications for health care reform. $J$ Palliat Med. 2013;16(11):1388-1393.

15. Keim-Malpass J, Stegenga K, Loudin B, Kennedy C, Kools S. "It's back! My remission is over": Online communication of disease progression among adolescents with cancer. J Pediatr Oncol Nurs. 2016;33(3): 209-217.

16. Keim-Malpass J, Steeves RH. Talking with death at a diner: young women's online narratives of cancer. Oncol Nurs Forum. 2012;39(4): 373-378, 406.

17. Kestler SA, Lobiondo-Wood G. Review of symptom experiences in children and adolescents with cancer. Cancer Nurs. 2012;35(2): E31-E49.

18. Keegan TH, Ries LA, Barr RD, et al. Comparison of cancer survival trends in the United States of adolescents and young adults with those in children and older adults. Cancer. 2016;122(7):1009-1016.

19. Shaw PH, Reed DR, Yeager N, Zebrack B, Castellino SM, Bleyer A. Adolescent and young adult (AYA) oncology in the United States: a specialty in its late adolescence. $J$ Pediatr Hematol Oncol. 2015;37(3):161-169.

20. Tai E, Buchanan N, Townsend J, Fairley T, Moore A, Richardson LC. Health status of adolescent and young adult cancer survivors. Cancer. 2012;118(19):4884-4891.

21. Pritchard S, Cuvelier G, Harlos M, Barr R. Palliative care in adolescents and young adults with cancer. Cancer. 2011;117(10 Suppl):2323-2328.
Adolescent Health, Medicine and Therapeutics

Publish your work in this journal

Adolescent Health, Medicine and Therapeutics is an international, peer-reviewed, open access journal focusing on health, pathology, and treatment issues specific to the adolescent age group. All aspects of health maintenance, preventative measures and disease treatment interventions are addressed within the journal and practitioners from all disciplines are

\section{Dovepress}

invited to submit their work as well as healthcare researchers and patient support groups. This journal is included in PubMed. The manuscript management system is completely online and includes a very quick and fair peer-review system. Visit http://www.dovepress.com/testimonials. php to read real quotes from published authors. 